\title{
Periodic-Review Policy for a 2-Echelon Inventory Problem with Seasonal Demand
}

\author{
Noppadon Sakulsom $^{\mathrm{a}}$ and Wipawee Tharmmaphornphilas ${ }^{\mathrm{b}, *}$ \\ Department of Industrial Engineering, Faculty of Engineering, Chulalongkorn University, Thailand \\ E-mail: anoppadon.sak@gmail.com, bwipawee.t@chula.ac.th (Corresponding author)
}

\begin{abstract}
This paper studies a two-level inventory system with one warehouse and $N$ retailers under seasonal demand. All locations apply periodic review base-stock policy with echelon stock concept. The objective is to determine an inventory policy with the minimum inventory cost respected to required service level. Three ways to determine inventory policies are proposed which are upper, lower and EOQ alternatives. Among these alternatives, it is found that upper-alternative policies tend to give the lowest cost which is around 17\% lower than other policies. EOQ-alternative policies give the lowest cost in some instances with zero ordering cost. However, lower-alternative policies lead to the lower demand loss, its highest average loss in one instance is $0.07 \%$ while other policies' loss can be as high as $0.22 \%$.
\end{abstract}

Keywords: Inventory systems, multi-echelon systems, seasonal demand, mixed-integer programming.

ENGINEERING JOURNAL Volume 22 Issue 6

Received 13 December 2017

Accepted 6 August 2018

Published 4 December 2018

Online at http:/ / www.engj.org/

DOI:10.4186/ej.2018.22.6.117 


\section{Introduction}

Managing inventory in a multi-echelon system is a very complex problem as it leads to a lot of decisions on many activities and constraints, i.e. what, how much, and when items should be stored at each location, i.e. retailers and warehouse or transported from warehouse to each retailer.

This paper focuses on an inventory system with a single warehouse and two retailers under seasonal demand. This system is a 2-echelon inventory system whose demand only occurs at retailers. Retailers are supplied by the warehouse and the warehouse is supplied by external suppliers. All locations are replenished with known lead time. The system is illustrated in Fig. 1. In the system, items are stored at both warehouse and retailers. The demand which is not satisfied by on-hand inventory is considered as demand loss.

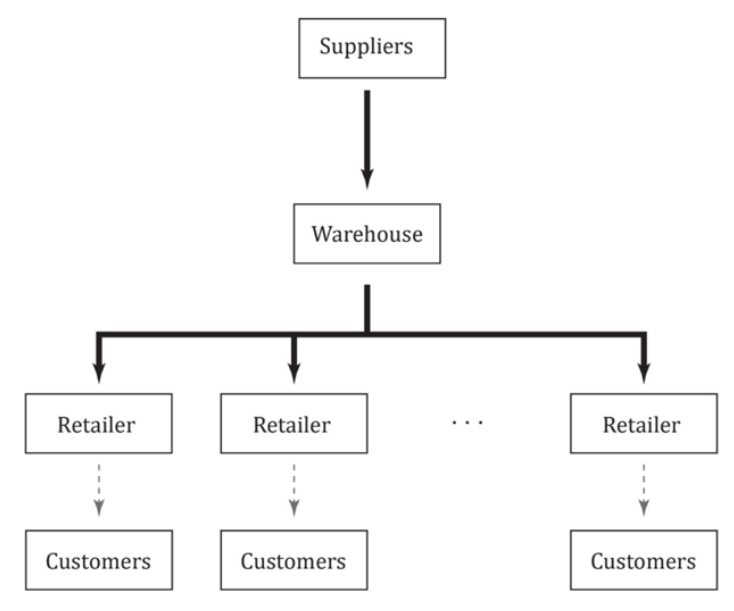

Fig. 1. An overview of the inventory system.

Demand is assumed to be seasonal without trend and fluctuating within a cycle of a certain span of periods. The demand pattern repeats itself cycle after cycle and, as there is no trend, the total demand per cycle is assumed to be stationary. Seasonal demands can occur as results from natural force or human decisions [1]. For example, the demand of skiing equipment is driven by weather conditions. On the other hand, department store sales are influenced by holidays and school calendars, which are based on human decision [2]. Dealing with seasonal demand as if it is stationary demand can lead to shortage or high holding cost. For example, in Table 1, system A calculates reorder point and order-up-to point by treating demand stationary with an average of 300 units/period. As an order is placed at the end of period and it will arrive at the end of next period, items are backlogged in periods 3,4 and 5. System B raises reorder and order-up-to points by 300 units to avoid shortage so there is no backlog but the total holding item is increased to 4,164 units. On the other hand, system $\mathrm{C}$ calculates ordering policy by considering seasonal demand. This policy leads to no backlog with the total holding item of 3,408 which is lower than system B. When demand pattern is clearly seasonal. If the ordering policy is developed without taking care of this seasonal pattern, it can lead either to shortage as system A or high holding cost as system B.

This paper considers the system operated under periodic review basis using $(R, S, S)$ or periodic review base-stock policy in which inventory level is reviewed every $R$ periods and when the level reaches $S$ or lower, an order must be placed to raise the inventory level back to equal or higher than $S$. The system controls inventory with echelon stock concept where each location makes its own decision. Each retailer knows its own inventory information while the warehouse can access information of every location. The objective of this paper is to develop an approach for determining a proper inventory policy for each location to minimize the total inventory cost.

The remainder of this paper is organized as follows. Section 2 reviews the literature related to multiechelon system. Section 3 presents a problem description. Section 4 describes the methodology to determine ordering policies. Section 5 presents results and discussions. Finally, section 6 concludes and suggests future research extensions. 
Table 1. The difference between treating demand as stationary and seasonal patterns.

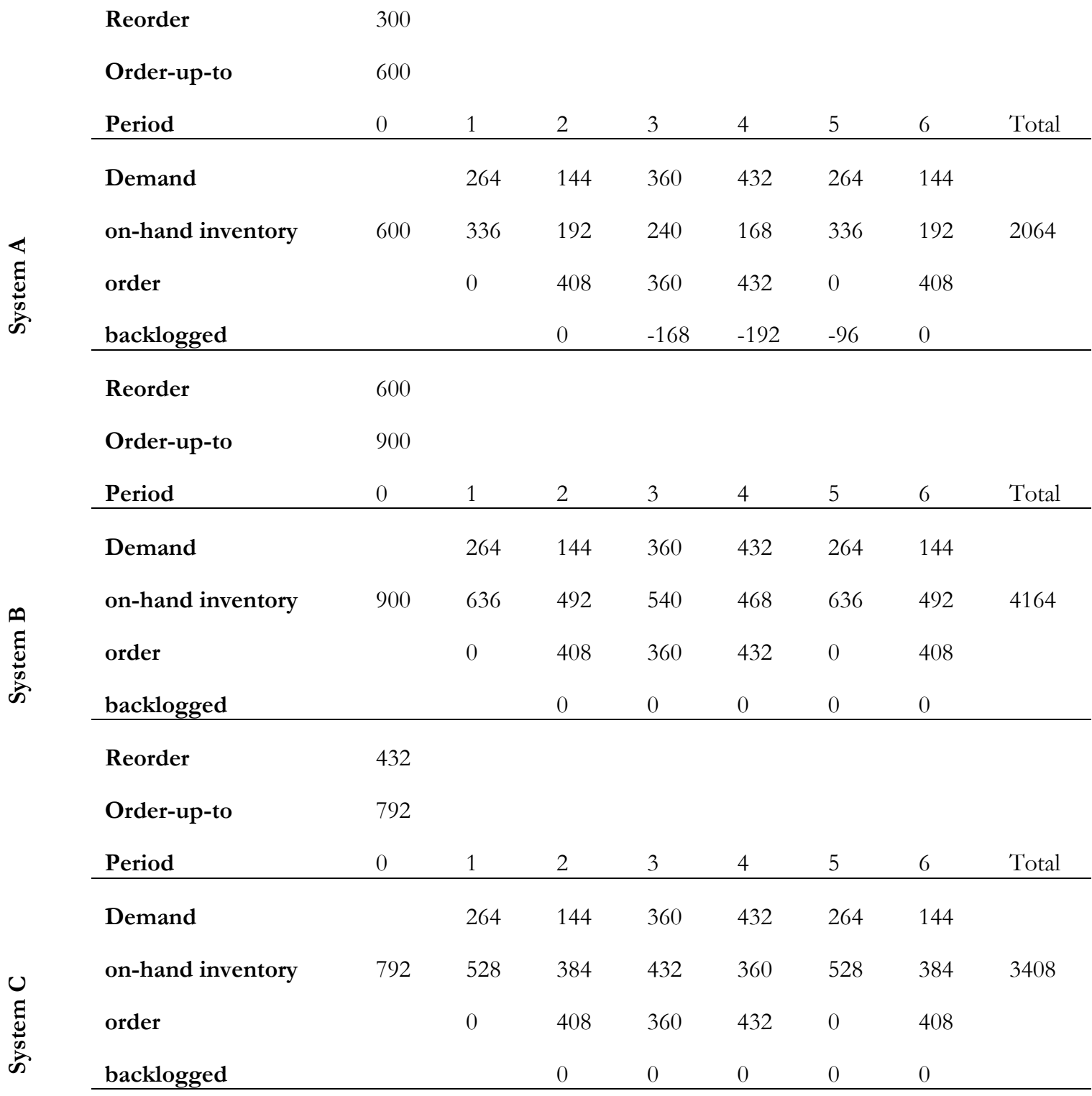

\section{Literature Review}

A multi-echelon system is more complex than a single-echelon system because demand at higher echelon, i.e. warehouse, is dependent on demand at lower echelons, i.e. retailers. Demand at warehouse is not directly required by customers but it is required by retailers to serve customers. When a warehouse manager makes decisions, he should consider not only demand and inventory levels at the warehouse, but also consider demand and inventory levels at retailers.

A multi-echelon model was first introduced as a serial multi-echelon system with stationary uncertain demand. Clark and Scarf [3] analyzed the system on multi-period time horizon by determining the optimal policy for each echelon separately. The system was extended from multi-period horizon to infinite time horizon using periodic base stock policies [4]. Besides the periodic review policies, De Bodt and Graves [5] applied a continuous review policy using reorder point and order quantity or so called $(s, Q)$. The model was later modified and proposed to apply to fast moving items by Mitra and Chatterjee [6]. From a serial inventory system, Bessler and Veinott [7] generalized the problem by including an arborescent structure - a divergent system that a stock point supplied multiple downstream stock points. The system was analyzed with periodic review ordering policies in multi-period time horizon. Then, the problem was extended to a divergent 2 echelon system with infinite horizon. The problem was studied in many different ways. For example, lower 
echelon locations were identical, and the demand was stationary and normally distributed [8]. Lower echelon locations were non-identical [9]. Period demands at end stock points were not normally distributed [10]. Demands had correlation over both location and time [11]. However, these studies assume stationary demand while ours assumes seasonal demand. Furthermore, there are some assumptions required in these studies such as nested policy which forces the lower echelon to order when higher echelon orders or no inventory at the higher echelon or no fixed ordering cost.

There are papers considering multi-echelon inventory system with fluctuating deterministic demand or so called a deterministic dynamic demand. Studies in this group were called the multi-echelon dynamic lot sizing problem which was extended with various additional constraints. They were mostly solved by mixed integer programming models or algorithms such as Lagrangian relaxation or decomposition strategy. Zangwill [12] applied an echelon concept to a multi-echelon dynamic lot sizing problem. Diaby and Martel [13] studied a system with transportation and product price discount based on order quantity. They developed a mixed integer programming model and used Lagrangian relaxation-based procedure to solve the problem. Jaruphongsa, Cetinkaya, and Lee [14] formulated a mixed integer programming model for a problem with time window constraint for demand delivery. They decomposed the problem into a sequence of smaller problems and developed an algorithm based on dynamic programming to solve them. Afzalabadi, Haji, and Haji [15] proposed heuristics for deterministic dynamic demand in infinite time horizon for a 2-echelon system. The heuristics determined the optimal length of finite time horizon and the optimum ordering pattern which led to the minimum cost within infinite horizon. The proposed heuristics gave better result than Silver-Meal algorithm and EOQ model proposed by Kovalev and $\mathrm{Ng}$ [16] which was developed for a discrete time inventory problem. Besides deterministic demand, some heuristics were developed based on mathematical models to solve uncertain demand. Tarim and Kingsman [17] developed an algorithm based on a mixed integer programming model to solve lot-sizing problem with service-level constraints for singleitem single location on multi-period. Their algorithm was improved from a strategy proposed by Bookbinder and Tan [18]. The algorithm decomposed a problem into two stages: (1) determine timing to replenish orders using expected demand of all periods and (2) adjust actual order size at the time of ordering when actual demand is realized. Tarim and Kingsman [19], then, applied the algorithm to calculate the $(R, S)$ policies for a single location with non-stationary demand system and Tarim and Smith [20] improved the algorithm to solve within shorter time by using a constraint programming model.

With non-stationary uncertain demand, there are studies both in single-echelon and multi-echelon systems. Although, there are various methods to deal with non-stationary demand, many methods are based on the same concept. One of the concepts that is widely used is dividing the non-stationary demand into many phases of stationary demand. In a multi-echelon system with non-stationary demand, Graves and Willems [21] proposed a model to determine locations to hold safety stock and size of safety stock at each location. The model was based on Grave and Willems [22] which was developed for a system with stationary demand. The model divided a planning horizon into many phases with different stationary demands. Then, safety stock for each phase was determined. The model also determined how safety stock levels changed from phase to phase. Reddy and Rajendran [23] developed heuristics to determine order-up-to policy for a 5-level serial supply chain with non-stationary demand at the lowest level. They proposed a dynamic orderup-to policy which the policy changed periodically. A simulation study was conducted to evaluate the heuristics in different settings. Kim, Wu, and Huang [24] applied a multi-period newsvendor model to a perishable product with non-stationary demand in a 2-echelon system. The model gave better solutions compared to those from single-period newsvendor and EOQ model. Grewal, Enns, and Rogers [25] applied simulation-optimization procedure to solve a single-echelon system with seasonal demand of two products. As demand had seasonal pattern which repeated cycle after cycle, each cycle could be divided into many phases with the same demand's character as other cycles. To correspond with demand in each phase, there were as many ordering policies as number of phases in a demand cycle. Therefore, reorder points and lot sizes varied along demand pattern regions. Ordering policy parameters were iteratively improved via process between simulation and optimization models.

Although many researchers chose to apply multiple ordering policies on a system with non-stationary demand, the number of decision conditions will grow rapidly if the system deals with many products and their demands change frequently. Due to complexity, multiple policies for non-stationary demands are not usually practical in real-life situations. The concept to apply different ordering policies to each phase of demand is proper when each demand phase is longer than review period and lead time. For example, when demand phase is 2,000 hours and lead time is 16 hours [25]. Tunc et al. [26] investigated that when demands followed a stable seasonal pattern with high uncertainty, stationary policies could reasonably substitute the 
optimal non-stationary policies. Stationary policies would be efficient in the system with high uncertain demand, high setup cost and low penalty cost. For more classification in multi-echelon inventory system, please refer to De Kok et al [27]. They classified multi-echelon inventory research systematically with various dimensions such as system structure, resource, demand, performance indicator, and research goal. They also identified research gap and potential future research based on recent technology development.

This paper studies a divergent 2-echelon system with seasonal demand. Since demand phase in our problem is one period or a length of each season is one period, which is shorter than a review period. Multiple policies as many papers used for seasonal demand may not be proper. Therefore, we choose to apply a single policy to our problem. The objective of this paper is to develop a methodology to determine ordering policies to minimize the total cost respected to expected service level.

\section{Problem Statement}

This section describes the problem and shows the model formulation to determine ordering policies. The problem considered is a 2-echelon inventory system having one warehouse and $N$ retailers with seasonal stochastic demand. Retailers are supplied by the warehouse and the warehouse is supplied by external suppliers. All locations are replenished with known lead time. Demand that is not satisfied with on-hand inventory will be considered as demand loss. The amount of loss must not exceed expected service level or, in this case, fill rate - the proportion of demand served from on-hand inventory [28].

Demand is assumed to be seasonal without trend and fluctuating within a cycle of a certain span of periods. The demand pattern repeats itself cycle after cycle as shown in Fig. 2. Period demands are assumed to be normally distributed. For example, in Fig. 2, each cycle consists of 4 periods. Average demand of periods 1, 5, 9 and 13 are normally distributed with the same parameters and so are periods 2, 6, 10 and 14 .

The system operates on periodic review basis using reorder point and order-up-to point or $(R, s, S)$. The system controls inventory with echelon stock basis which means each location makes decision on its own inventory information and the information of all locations downstream. This paper proposes a methodology to find optimal inventory policy based on $(R, S, S)$ system to minimize ordering and holding cost respected to expected service level.

Since we consider stochastic demand, it is difficult to find the optimal solution by using a mathematical model. However, a mixed integer programming model is developed to clarify the problem.

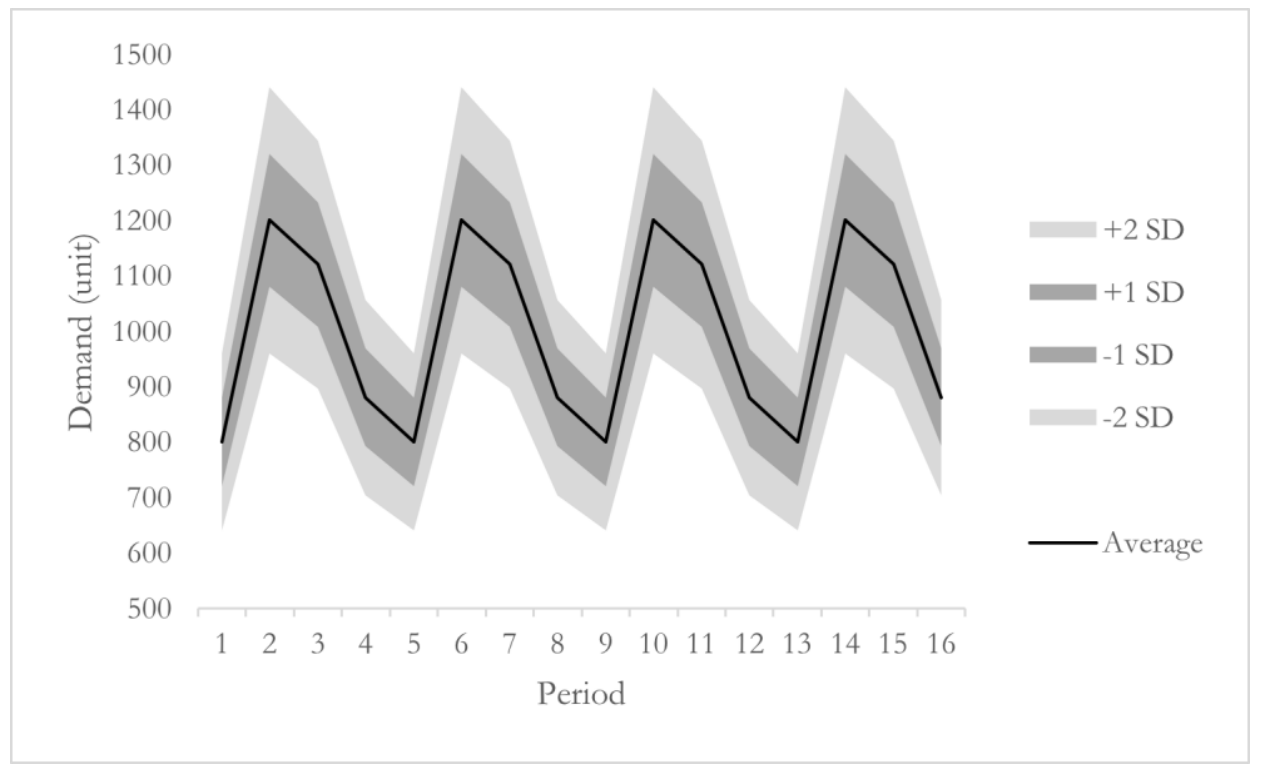

Fig. 2. Demand pattern.

The model objective is to minimize the total cost due to ordering and holding costs. A mixed-integer programming model is as follows.

Indices

Ir $\quad$ is a set of retailers $\{1,2, \ldots, n\}$ 
Irw is a set of stock points including a warehouse and retailers $\{0,1, \ldots, n\}$

(the warehouse is referred as $i=0$ )

$J \quad$ is a set of periods $\{1,2, \ldots, m\}$

Parameters

demand $_{i j} \quad=$ Demand of retailer $i$ in period $j$ (units)

costorder $_{i}=$ Ordering cost of stock point $i(\$)$

costholding $_{i}=$ Holding cost of stock point $i(\$ /$ unit $/$ period $)$

$t_{i} \quad=$ Lead time of stock point $i$ (periods)

servlevel $_{i}=$ Expected service level of retailer $i$

$r_{i j} \quad=1$ if stock point $i$ reviews its inventory in period $j$;

0 otherwise

$M_{i} \quad=$ A positive number that is greater than the total demand in planning horizon

of stock point $i$

Decision variables

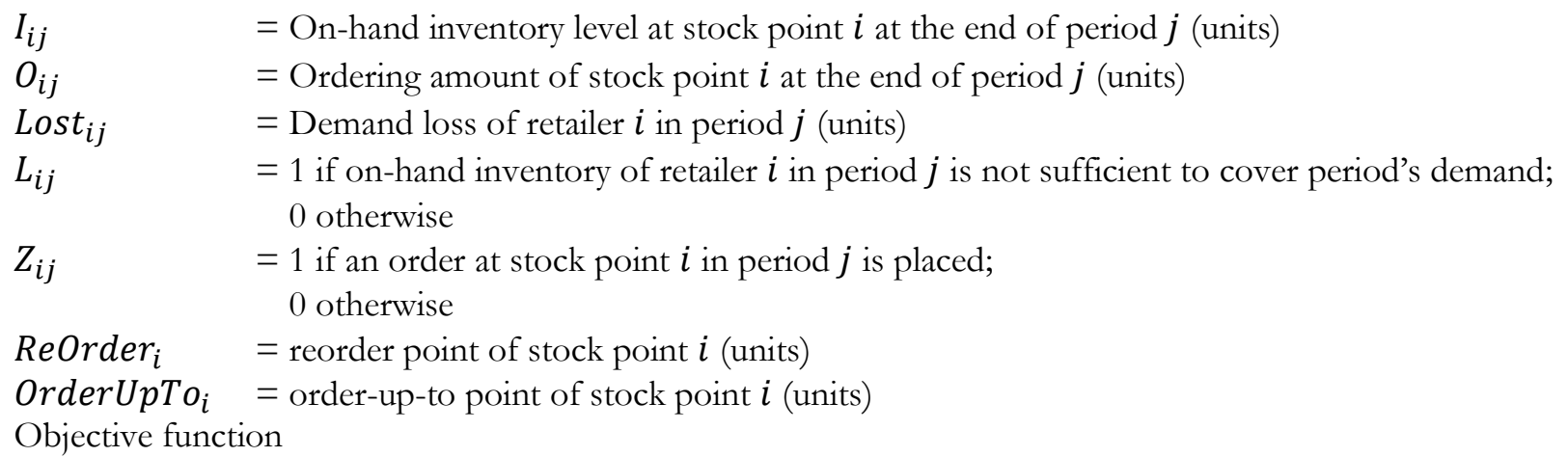

Minimize $\quad \sum_{i=0}^{n} \sum_{j=1}^{m} Z_{i j} \times$ costorder $_{i}+\sum_{i=0}^{n} \sum_{j=1}^{m} I_{i j} \times$ costholding $_{i}$

Subject to

$$
\begin{array}{ll}
I_{i j-1}+O_{i j-t_{i}}+\text { Lost }_{i j}=\text { demand }_{i j}+I_{i j} & \forall i \in I r, \forall j \in J \\
I_{0 j-1}+O_{0 j-t_{0}}=\sum_{i=1}^{n} O_{i j}+I_{0 j} & \forall j \in J \\
\text { demand }_{i j}-\left(I_{i j-1}+O_{i j-t_{i}}\right) \leq L_{i j} \times M_{i} & \forall i \in I r, \forall j \in J \\
\left(I_{i j-1}+O_{i j-t_{i}}\right)-\text { demand }_{i j} \leq\left(1-L_{i j}\right) \times M_{i} & \forall i \in I r, \forall j \in J \\
\text { Lost }_{i j} \leq L_{i j} \times M_{i} & \forall i \in I r, \forall j \in J \\
I_{i j} \leq\left(1-L_{i j}\right) \times M_{i} & \forall i \in I r, \forall j \in J \\
Z_{i j} \times r_{i j} \times M_{i} \geq O_{i j} & \forall i \in I r w, \forall j \in J \\
I_{i j-1}+\sum_{l=j-t_{i}}^{j-1} O_{i l}+\left(Z_{i j}+\left(1-r_{i j}\right)\right) \times M_{i}-0.5 \geq \operatorname{ReOrder}_{i} & \forall i \in I r, \forall j \in J \\
I_{i j-1}+\sum_{l=j-t_{i}}^{j-1} O_{i l} \leq \operatorname{ReOrder}_{i}+\left(1-Z_{i j}\right) \times M_{i} & \forall i \in I r, \forall j \in J \\
I_{i j-1}+\sum_{l=j-t_{i}}^{j} O_{i l}+\left(1-Z_{i j}\right) \times M_{i} \geq \text { OrderUpTo }_{i} & \forall i \in I r, \forall j \in J \\
I_{i j-1}+\sum_{l=j-t_{i}}^{j} O_{i l} \leq \text { OrderUpTo }_{i}+\left(1-Z_{i j}\right) \times M_{i} & \forall i \in I r, \forall j \in J \\
\sum_{i=0}^{n} I_{i j-1}+\sum_{i=0}^{n} \sum_{l=j-t_{i}}^{j-1} O_{i l}+\left(Z_{0 j}+\left(1-r_{0 j}\right)\right) \times M_{i}-0.5 \geq \operatorname{ReOrder}_{0} \\
\sum_{i=0}^{n} I_{i j-1}+\sum_{i=0}^{n} \sum_{l=j-t_{i}}^{j-1} O_{i l} \leq \operatorname{ReOrder}_{0}+\left(1-Z_{0 j}\right) \times M_{i} & \forall j \in J \\
\sum_{i=0}^{n} I_{i j-1}+\sum_{i=0}^{n} \sum_{l=j-t_{i}}^{j-1} O_{i l}+O_{0 j}+\left(1-Z_{0 j}\right) \times M_{i} \geq \text { OrderUpTo }_{0} & \forall j \in J \\
\sum_{i=0}^{n} I_{i j-1}+\sum_{i=0}^{n} \sum_{l=j-t_{i}}^{j-1} O_{i l}+O_{0 j} \leq \text { OrderUpTo }_{0}+\left(1-Z_{0 j}\right) \times M_{i} & \forall j \in J
\end{array}
$$


$1-\frac{\text { Lost }_{i j}}{\text { demand }_{i j}} \geq$ servlevel $_{i}$

$$
\begin{aligned}
& \forall i \in I r, \forall j \in J \\
& \forall i \in I r w, \forall j \in J \\
& \forall i \in I r w, \forall j \in J
\end{aligned}
$$

The objective function (1) is to minimize the total cost of a system due to ordering and holding costs. Constraints (2) are inventory levels and product flows in and out (and also loss) at each retailer in each period and constraints (3) are inventory levels and product flows in and out at the warehouse. It is assumed that the warehouse always has sufficient items for retailers' orders so there is no demand loss at the warehouse. Constraints (4) to (7) force decision variables Lost $_{i j}$ and $I_{i j}$. If available inventory at the retailer is sufficient to serve period's demand, $L_{i j}$ will be zero and $L_{o s} t_{i j}$ will be zero; otherwise, $L_{i j}$ will be 1 and $I_{i j}$ will be zero. Constraints (8) define that, on review period $\left(r_{i j}=1\right)$, if retailer(s) or warehouse place order, fixed ordering costs will occur. If it is not on review period $\left(r_{i j}=0\right)$, order amount, $O_{i j}$, will be zero. In constraints (9) through (16), reorder points and order-up-to points for the stock points are defined. Constraints (9) to (12) are applied to retailers, while constraints (13) to (16) are applied to the warehouse. Constraints (9) and (10) force the retailers to place orders when their inventory positions (the total level of items on-hand and onorder) are less than or equal to the reorder points and there must be no order placed when inventory positions are higher than the reorder points. In constraints (9), if the inventory positions are equal to or lower than reorder points and $r_{i j}=1, Z_{i j}$ will be 1 . If $r_{i j}=0, Z_{i j}$ will be either 1 or 0 where it tends towards 0 due to the objective function. There is a -0.5 term on the left-hand side because, without this term, when the inventory position is equal to reorder points, $Z_{i j}$ can be either 0 or 1 which means that it might be no order placed. In constraints (10), on the other hand, if the inventory positions are higher than reorder points, $Z_{i j}$ will be 0 . Constraints (11) and (12) force the inventory positions after placing orders to be equal to the orderup-to points. In these two constraints, if $Z_{i j}=0$, the constraints will always be true. In constraints (11), when an order is placed or $Z_{i j}=1$, the inventory level plus order must not less than the order-up-to point. Besides, in constraints (12), the inventory level plus order must not exceed the order-up-to point. Constraints (13) through (16) are similar to constraints (9) to (12) but they are applied to the warehouse. The major difference between the warehouse and retailers is that, at the warehouse, an echelon stock concept is applied so the inventory level is the summation of inventory on-hand and on-order in the system. The echelon stock concept is applied to the warehouse since demands occur only at retailers. Without information of inventory level at retailers, the warehouse must hold stock sufficient to fill retailers' orders all the time which leads to higher holding cost. By applying the echelon stock concept, the warehouse can predict when retailers are about to place orders and can manage to fill its inventory just before those orders are placed. Constraints (17) guarantee service level for every retailer. Constraints (18) and (19) force all decision variables to be either positive values or binary.

\section{Methodology}

Since the system has stochastic seasonal demand, it cannot be directly solved by a mixed integer programming model. Like an approach proposed by Bookbinder and Tan [18], they proposed methodology composed of 2 phases - (1) determine timing of replenishment and number of periods to cover (2) determine safety stocks. We propose a 2-phase methodology. The first phase calculated the deterministic policies by using average period demand. These deterministic policies are used to determine when to order and the number of period's demands which the order quantity covers. The second phase is finding appropriate safety stock levels based on the deterministic policies from the first phase to absorb variability of stochastic demand. Safety stock levels can be determined by solving various demand scenarios.

\subsection{Determining Policy for Deterministic Demand Component}

This phase is used to determine when to order and the number of periods which the order quantity covers their demand. Since demand is assumed deterministic, policies are determined based on average demand. 


\subsubsection{Concepts for determining initial ordering policy}

Since a mixed integer programming model in Section 3 is used to determine deterministic policies. The problem is solved within finite-period horizon while real-life system lies within infinite period. A conflict emerges when an infinite horizon problem is solved using finite horizon. While there is no demand after the planning time horizon, on-hand inventory level at the last period tends to be zero which gives lower holding cost. Applying this type of solutions to an infinite-horizon problem may lead to shortage at the period beyond the considered horizon. Therefore, constraints (20) and (21) are added to the MIP model to force on-hand and on-order inventory at the beginning to be equal to those at the end of horizon. Noted that, in case of stationary demand, the planning horizon can be any periods since every period has the same average demand. However, since we consider seasonal demand, each period has different average demand so on-hand and onorder inventory at the end of horizon must come from the same period of a cycle as the period at the beginning of the horizon. Due to this concept, the planning horizon must be the multiple of cycles.

$$
\begin{aligned}
& I_{i 0}=I_{i m} \\
& O_{i 0}=O_{i m}
\end{aligned}
$$

$\forall i \in \operatorname{Ir} w$

$\forall i \in \operatorname{Ir} w$

\subsubsection{Alternatives for determining initial ordering policy}

As the system operates on periodic review basis or $(R, s, S)$ policy, there can be alternative solutions for each problem which provide the same minimum total cost. For example, the problem with 4-period demand cycle shown in Table 2 has reorder point of 480 and order-up-to point of 4480 . Since an order will be placed whenever the inventory position reaches the reorder point or below to raise the level up to the order-up-to point, the inventory position will raise to the same level no matter how many on-hand items at the time. Therefore, the reorder points between 480 to 1,359 with the same order-up-to point of 4,480 give the same result as shown in Table 2. Although, both 480 and 1,359 reorder points give the same results in this deterministic phase, they can lead to different safety stocks in the second phase which means the different total costs.

Table 2. Example of alternative solutions.

\begin{tabular}{llllllllll}
\hline Period & 0 & 1 & 2 & 3 & 4 & 5 & 6 & 7 & 8 \\
\hline Demand & & 880 & 480 & 1200 & 1440 & 880 & 480 & 1200 & 1440 \\
\hline on-hand inventory & 1360 & 480 & 4000 & 2800 & 1360 & 480 & 4000 & 2800 & 1360 \\
\hline on-order inventory & 0 & 4000 & 0 & 0 & 0 & 4000 & 0 & 0 & 0 \\
\hline inventory position & 1360 & 4480 & 4000 & 2800 & 1360 & 4480 & 4000 & 2800 & 1360 \\
\hline
\end{tabular}

With these alternative solutions, there are 2 policies obtained from the model. We name them lower policy and upper policy. The lower one is the policy with the lowest value of reorder point or 480 units in this case and the upper one is the policy with highest value or 1,359 units. The lower and upper policies will apply to all stock points in the system. To obtain lower-alternative policy, the objective function is modified as follow. The objective function (22) is the original function modified as a goal programming model of which the main objective is minimizing the total cost weighted by $W_{\text {cost }}$ and the secondary objective is minimizing reorder point. The value of $W_{\text {cost }}$ should be high enough to dominate sum of the reorder points.

Minimize $\quad W_{\text {cost }} \times\left(\sum_{i=0}^{n} \sum_{j=1}^{m} Z_{i j} \times\right.$ costorder $_{i}+\sum_{i=0}^{n} \sum_{j=1}^{m} I_{i j} \times$ costholding $\left._{i}\right)$ $+\sum_{i=0}^{n}$ ReOrder $_{i}$

On the other hand, upper-alternative policy can be obtained via another modified objective function (23).

Minimize

$$
W_{\text {cost }} \times\left(\sum_{i=0}^{n} \sum_{j=1}^{m} Z_{i j} \times \text { costorder }+\sum_{i=0}^{n} \sum_{j=1}^{m} I_{i j} \times \text { costholding }_{i}\right)
$$




$$
-\sum_{i=0}^{n} \operatorname{ReOrder}_{i}
$$

To compare the quality of solutions, one more policy is developed based on EOQ concept. A solution with EOQ concept is determined by forcing the difference between reorder point and order-up-to point at each retailer equal to EOQ. Constraints (24) is added to the model to force the difference between orderup-to and reorder points close to EOQ value. The diff $_{i}^{+}$is positive when the difference between order-upto point and reorder point is greater than EOQ. An EOQ-alternative policy is determined with the objective function (25). In this case, the different between order-up-to point and reorder point equals to EOQ is the main objective. Therefore, $W_{E O Q}$ must be high enough to dominate another objective.

$$
\left(\text { OrderUpto }_{i}-\text { ReOrder }_{i}\right)-\operatorname{eoq}_{i}=\operatorname{diff}_{i}^{+}-\operatorname{diff}_{i}^{-} \quad \forall i \in \operatorname{Ir}
$$

Minimize

$$
\begin{gathered}
\sum_{i=0}^{n} \sum_{j=1}^{m} Z_{i j} \times \text { costorder } \\
+\sum_{i=0}^{n} \sum_{j=1}^{m} I_{i j} \times \text { costholding }_{i} \\
+W_{E O Q} \times\left(\text { diff }_{i}^{+}-\text {diff }_{i}^{-}\right)
\end{gathered}
$$

Therefore, there are 3 alternative policies for each instance from the first phase. After determining initial policies for each instance, each policy will be used as input to determine safety stock levels to deal with uncertain component of demand in the next phase.

\subsection{Determining Safety Stock for Random Demand Component}

Since demand is normally distributed, solution from the first phase which based on average demand may not achieve expected service level in various scenarios. In this phase, safety stock levels are calculated for all stock points to absorb variability of demand.

Various scenarios of demand are generated from the normal distribution and a set of scenarios is solved simultaneously with a MIP model to find safety stock level by using ordering policy from the previous model as input parameters. Those input parameters are determReorder ${ }_{i}$, determOrderUpTo dinitial $_{i}$ and initialO $_{i l}$. Reorder points and order-up-to points of final ordering policy are reorder points and order-upto points from initial policy plus safety stock.

The model in this phase is developed based on the model in the previous section with some adjustment to deal with multiple scenarios and demand loss. Additional indices, parameters and decision variables are as follows.

Additional indices

$S \quad$ is a set of scenarios $\{1,2, \ldots, t\}$

$L \quad$ is a set of periods $\left\{-\max \left\{\right.\right.$ leadTime $\left.\left._{i}\right\}+1, \ldots, 0\right\}$

Additional parameters

$\begin{array}{ll}\text { demand }_{s i j} & =\text { Demand of retailer } i \text { in period } j \text { of scenario } s \text { (units) } \\ \text { initialI }_{i} & =\text { Initial on-hand inventory level of stock point } i \text { (units) } \\ \text { initialO }_{i l} & =\text { Initial on-order of stock point } i \text { on period } l \text { (units) } \\ \text { determReorder }_{i} & =\text { Deterministic reorder point of stock point } i \text { (units) } \\ \text { determOrderUpTo }_{i} & =\text { Deterministic Order-Up-To point of stock point } i \text { (units) }\end{array}$

Additional decision variables

$I_{s i j} \quad=$ Inventory level at stock point $i$ at the end of period $j$ of scenario $S$ (units)

$O_{s i j} \quad=$ Ordering amount of stock point $i$ at the end of period $j$ of scenario $s$ (units)

Lost $_{s i j} \quad=$ Demand loss of retailer $i$ in period $j$ of scenario $s$ (units)

$L_{s i j} \quad=1$ if on-hand inventory of retailer $i$ in period $j$ of scenario $s$ is not sufficient to cover period's demand; 
0 otherwise

$Z_{s i j} \quad=1$ if regular order at stock point $i$ in period $j$ of scenario $s$ is placed; 0 otherwise

$S S_{i} \quad=$ Safety stock of stock point $i$ (units)

Objective function

Minimize

$\sum_{s=1}^{t} \sum_{i=0}^{n} \sum_{j=1}^{m} Z_{s i j} \times$ costorder $i+\sum_{s=1}^{t} \sum_{i=0}^{n} \sum_{j=1}^{m} I_{s i j} \times$ costholding $_{i}$

Subject to

$$
\begin{aligned}
& I_{s i j-1}+O_{s i j-t_{i}}+\text { Lost }_{s i j}=\text { demand }_{s i j}+I_{s i j} \\
& I_{s 0 j-1}+O_{s 0 j-t_{0}}=\sum_{i=1}^{n} O_{s i j}+I_{s 0 j} \\
& \text { demand }_{s i j}-\left(I_{s i j-1}+O_{s i j-t_{i}}\right) \leq L_{s i j} \times M_{i} \\
& \left(I_{s i j-1}+O_{s i j-t_{i}}\right)-\text { demand }_{s i j} \leq\left(1-L_{s i j}\right) \times M_{i} \\
& \forall i \in I r, \forall j \in J, \forall s \in S \\
& \forall j \in J, \forall s \in S \\
& \forall i \in I r, \forall j \in J, \forall s \in S \\
& \forall i \in I r, \forall j \in J, \forall s \in S \\
& \text { Lost }_{s i j} \leq L_{s i j} \times M_{i} \\
& I_{s i j} \leq\left(1-L_{s i j}\right) \times M_{i} \\
& \forall i \in I r, \forall j \in J, \forall s \in S \\
& \forall i \in I r, \forall j \in J, \forall s \in S \\
& Z_{s i j} \times r_{i j} \times M_{i} \geq O_{s i j} \\
& I_{s i j-1}+\sum_{l=j-t_{i}}^{j-1} O_{s i l}+\left(Z_{s i j}+\left(1-r_{i j}\right)\right) \times M_{i}-0.5 \geq \text { ReOrder }_{i} \\
& \forall i \in \operatorname{Ir} w, \forall j \in J, \forall s \in S \\
& I_{s i j-1}+\sum_{l=j-t_{i}}^{j} O_{s i l} \leq \operatorname{OrderUpTo}_{i}+\left(1-Z_{s i j}\right) \times M_{i} \quad \forall i \in I r, \forall j \in J, \forall s \in S \\
& \sum_{i=0}^{n} I_{s i j-1}+\sum_{i=0}^{n} \sum_{l=j-t_{i}}^{j-1} O_{s i l}+\left(Z_{s 0 j}+\left(1-r_{0 j}\right)\right) \times M_{i}-0.5 \geq \text { ReOrder }_{0} \\
& \forall j \in J, \forall s \in S \\
& \sum_{i=0}^{n} I_{i j-1}+\sum_{i=0}^{n} \sum_{l=j-t_{i}}^{j-1} O_{s i l} \leq \text { ReOrder }_{0}+\left(1-Z_{s 0 j}\right) \times M_{i} \quad \forall j \in J, \forall s \in S \\
& \sum_{i=0}^{n} I_{s i j-1}+\sum_{i=0}^{n} \sum_{l=j-t_{i}}^{j-1} O_{s i l}+O_{s 0 j}+\left(1-Z_{0 j}\right) \times M_{i} \geq \operatorname{OrderUpTo}_{0} \\
& \sum_{i=0}^{n} I_{i j-1}+\sum_{i=0}^{n} \sum_{l=j-t_{i}}^{j-1} O_{s i l}+O_{s 0 j} \leq \operatorname{OrderUpTo} o_{0}+\left(1-Z_{s 0 j}\right) \times M_{i} \\
& \forall j \in J, \forall s \in S \\
& \forall j \in J, \forall s \in S
\end{aligned}
$$

The objective function (26) is to minimize the total cost of the system in all scenarios due to ordering cost and holding cost. Constraints (27) through (42) force variables in the same way as constraints (2) to (17). Constraints (43) and (44) calculate reorder points and order-up-to points of the final policy. Constraints (45) force initial on-hand inventory, $I_{s i 0}$, equal to an initial amount obtained from the previous model plus safety stock. Constraints (46) force initial on-order before the first period, $O_{\text {sil }}$, equal to an initial amount obtained from the previous model, initialO $i l$. Constraints (47) and (48) force all decision variables to be either positive values or binary. 


\section{Experimental Results and Discussion}

The experiment summary is shown in Fig. 3. To test the proposed methodology, in the first phase, six instances are developed. Three instances have 4-period cycle and the others have 7-period cycle. Each group of three instances has the same period-cycle demand pattern and holding cost but different ordering costs: high, low and zero. High value is ordering costs of which EOQ values close to the retailers' cycle demand and low value is costs of which EOQ values smaller than the cycle demand. Certainly, the zero value is an ordering cost with value of zero. In Fig. 3, the ordering cost and holding cost ratios are shown for each location as (WH, R1, R2) which means the warehouse, retailer1 and retailer2. In all instances, holding cost is 1 (\$/unit/period). Demand pattern for each retailer is also shown as average demand in each period. These six instances are solved using an MIP model in phase I to find the best reorder and order-up-to points for average demand under three initial policies. These three initial policies are lower, upper and EOQ discussed in section 4.1.2. Since the horizon must be multiples of cycles, 6-cycle planning horizon is used in this phase. Therefore, the 4-period cycle instances have 24-period horizon and the 7-period cycle instances have 42-period horizon. The MIP models were solved by using CPLEX. All experiments ran on a computer with $2.00 \mathrm{GHz}$ Intel Core i7 processor and $4 \mathrm{~GB}$ of RAM.

In the second phase, 3 different standard deviations are used to generate various scenarios of the problem, i.e. $10 \%, 20 \%$ and $25 \%$ of average demand. We assumed that demands are normally distributed. Demand in each period is randomly generated based on average and standard deviation of that period. Demand of the 1 st period in every cycle has the same average and standard deviation. This also applies to the $2^{\text {nd }}, 3^{\text {rd }}$ and so on. A set of 4 scenarios is randomly generated based on the same parameters and solved for safety stock with the second MIP model. Since they are randomly generated, actual demand in each scenarios is different. Each scenario has 24-cycle horizon which is 96-period horizon for 4-period instance and 168-period horizon for 7-period instance. The instance with 4-period cycle under $99 \%$ is used as the base case. Then a 4-period cycle under 95\% service level is used to measure the differences between service levels. Furthermore, the instances with 7-period cycle under $99 \%$ service level is used to measure the differences between the number of periods in cycle.

After final policy is developed from the second phase, the performance of the policy is tested with additional 1,000-period scenario to investigate whether demand loss is within expected service level.

\subsection{Comparison among the Lower, Upper and EOQ Alternatives}

Under both 99\% and 95\% service level, in 4-period cycle instances, all three alternatives perform the same way. Comparing upper and lower policies, upper policy gives the lower total cost in every scenarios. The upper policy could give lower total costs since it has higher reorder points which lead to lower safety stock in the second model. Since the upper and lower policies have different reorder points but the same orderup-to points. Although reorder points are raised by safety stock to the same levels, the upper policies will have lower final order-up-to points which lead to smaller sizes of orders and lower holding costs. In case of zero ordering cost, EOQ policy gives the lowest total cost. In this case, EOQ is zero which means reorder points and order-up-to points of retailers in EOQ policy are the same points. It means that the policy of retailers are $(R, S)$ instead of $(R, S, S)$ and they have inventory position filled at order-up-to point in every period, which leads to low holding cost and low total cost since ordering cost is zero. The average differences in costs are shown in Table 3 and Table 4. The average difference from the best solution is calculated from 4 scenarios, so alternatives with $0.00 \%$ difference are the alternatives that perform better than the others in all 4 scenarios. However, in some case, one alternative may outperform other alternatives in some scenarios when another alternative outperforms it in other scenarios. For example, in Table 3, at high ordering cost and SD to demand average ratio of $25 \%$, upper policy gives better results than EOQ policy in 3 scenarios and the EOQ policy performs better in 1 scenario. Therefore, upper-alternative difference is $0.01 \%$ and EOQ-alternative difference is $0.61 \%$.

Generally, in Table 3 and Table 4, most instances can be solved within 5 minutes but, in some cases, it can take almost an hour. It takes longer time to solve an instance with low service level than an instance with high service level. Since lower service level means higher demand loss allowed, the search space is larger than those problems with higher service level. As there are more options to be chosen, it takes longer time to find the optimal solution. 
Furthermore, in 7-period cycle instances, upper policy also gives lower total cost than lower policy in all scenarios as shown in Table 5. However, in case of zero ordering cost, all three alternatives receive the same policy with the same total cost in phase 1 but the upper policy has the highest reorder points at the warehouse. Therefore, when their reorder points are raised by safety stock to the same values, the upper policy has the lowest order-up-to points in phase 2 which leads to the lowest holding costs.

Most instances in Table 5 can be solved within 15 minutes but, in some cases, it can take up to 3 hours. Comparing computational time, the problems with longer planning horizon require longer computational time. For example, the instances with 168-period planning horizon require 1527.89 seconds on average which is longer than $224.24 \mathrm{~s}$ required by the instances with 96-period horizon. Details of all scenarios' costs and computational time are provided at http://pioneer.netserv.chula.ac.th/ twipawee/RsS_MIP.zip

Policy Determination

\begin{tabular}{|c|c|c|c|}
\cline { 2 - 3 } \multicolumn{1}{c|}{} & \multicolumn{2}{c|}{ Average demand in each period } & \multicolumn{1}{c|}{ Ordering cost/ } \\
Period/cycle & Retailer 1 & Retailer 2 & $\begin{array}{c}\text { Holding cost } \\
\text { (WH, R1, R2) }\end{array}$ \\
\hline 4 & $880,480,1200,1440$ & $880,1840,2400,2880$ & High $(12,000,12,000,12,000)$ \\
\hline 4 & $880,480,1200,1440$ & $880,1840,2400,2880$ & Low $(750,750,750)$ \\
\hline 4 & $880,480,1200,1440$ & $880,1840,2400,2880$ & Zero $(0,0,0)$ \\
\hline 7 & $105,99,109,121,88,140,38$ & $226,228,220,209,159,287,71$ & High $(2,450,2,450,4,900)$ \\
\hline 7 & $105,99,109,121,88,140,38$ & $226,228,220,209,159,287,71$ & Low $(612.5,612.5,1225)$ \\
\hline 7 & $105,99,109,121,88,140,38$ & $226,228,220,209,159,287,71$ & Zero $(0,0,0)$ \\
\hline
\end{tabular}

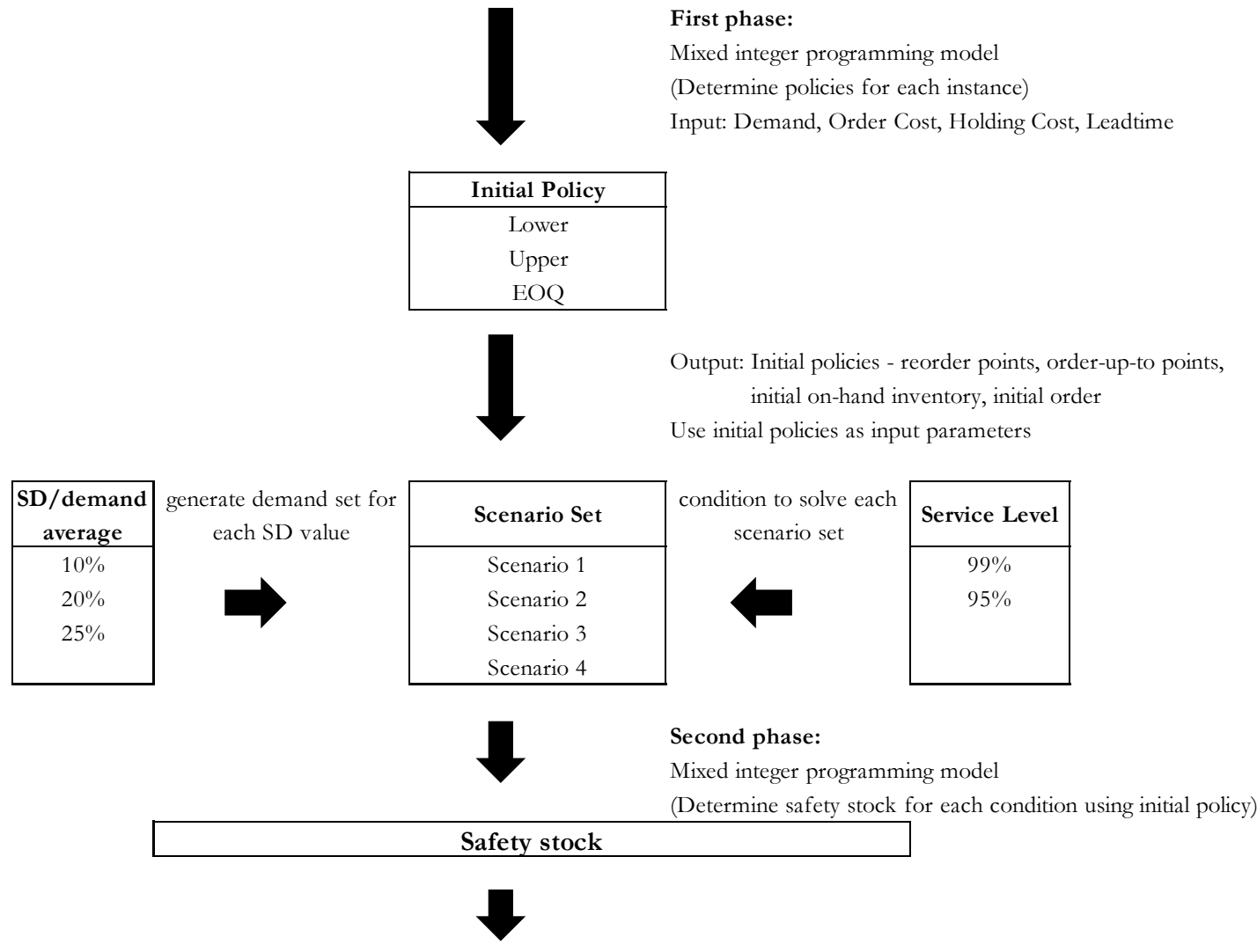

Output: Final policies - reorder points, order-up-to points, initial on-hand inventory, initial order, safety stock

Policy Evaluation

Test on 1,000-period scenario

Fig. 3. Experimental summary. 
Table 3. Average difference and computational time for 4-period cycle instances at 99\% service level.

\begin{tabular}{|c|c|c|c|c|c|c|c|c|}
\hline & & & $\begin{array}{l}\text { Averag } \\
\text { from B }\end{array}$ & $\begin{array}{c}\% \\
\text { Solution }\end{array}$ & Difference & $\begin{array}{l}\text { Compu } \\
\text { Time (s }\end{array}$ & ional & \\
\hline Service Level & $\begin{array}{l}\text { Ordering Cost/ } \\
\text { Holding Cost }\end{array}$ & $\begin{array}{l}\text { SD/ } \\
\text { Average }\end{array}$ & Upper & Lower & EOQ & Upper & Lower & EOQ \\
\hline 0.99 & High & $10 \%$ & $0.00 \%$ & $14.64 \%$ & $10.39 \%$ & 148.52 & 110.03 & 94.14 \\
\hline & & $20 \%$ & $0.00 \%$ & $3.61 \%$ & $1.18 \%$ & 70.73 & 93.31 & 70.86 \\
\hline & & $25 \%$ & $0.01 \%$ & $4.46 \%$ & $0.61 \%$ & 158.42 & 91.94 & 113.72 \\
\hline & Low & $10 \%$ & $0.00 \%$ & $26.84 \%$ & $12.72 \%$ & 2641.00 & 111.80 & 286.22 \\
\hline & & $20 \%$ & $0.00 \%$ & $19.54 \%$ & $11.09 \%$ & 124.95 & 95.75 & 234.00 \\
\hline & & $25 \%$ & $0.00 \%$ & $18.29 \%$ & $11.01 \%$ & 126.12 & 138.34 & 110.75 \\
\hline & Zero & $10 \%$ & $6.82 \%$ & $35.97 \%$ & $0.00 \%$ & 125.69 & 195.44 & 106.02 \\
\hline & & $20 \%$ & $9.60 \%$ & $30.18 \%$ & $0.00 \%$ & 96.38 & 104.39 & 60.38 \\
\hline & & $25 \%$ & $8.07 \%$ & $27.48 \%$ & $0.00 \%$ & 61.55 & 411.69 & 72.31 \\
\hline
\end{tabular}

Table 4. Average difference and computational time for 4-period cycle instances at 95\% service level.

\begin{tabular}{|c|c|c|c|c|c|c|c|c|}
\hline \multirow[b]{2}{*}{ Service Level } & \multirow[b]{2}{*}{$\begin{array}{ll}\text { Ordering } & \text { Cost/ } \\
\text { Holding Cost } & \\
\end{array}$} & \multirow[b]{2}{*}{$\begin{array}{l}\text { SD/ } \\
\text { Average }\end{array}$} & \multicolumn{3}{|c|}{$\begin{array}{l}\text { Average } \% \quad \text { Difference } \\
\text { from Best Solution }\end{array}$} & \multicolumn{3}{|c|}{$\begin{array}{l}\text { Computational } \\
\text { Time (s) }\end{array}$} \\
\hline & & & Upper & Lower & EOQ & Upper & Lower & EOQ \\
\hline \multirow[t]{9}{*}{0.95} & High & $10 \%$ & $0.00 \%$ & $14.74 \%$ & $10.44 \%$ & 1576.31 & 242.22 & 143.74 \\
\hline & & $20 \%$ & $0.00 \%$ & $3.55 \%$ & $1.30 \%$ & 108.73 & 172.39 & 74.34 \\
\hline & & $25 \%$ & $0.10 \%$ & $4.27 \%$ & $0.39 \%$ & 112.86 & 77.00 & 1625.42 \\
\hline & Low & $10 \%$ & $0.00 \%$ & $27.02 \%$ & $12.77 \%$ & 687.84 & 144.97 & 1191.17 \\
\hline & & $20 \%$ & $0.00 \%$ & $19.75 \%$ & $11.39 \%$ & 127.03 & 117.03 & 271.11 \\
\hline & & $25 \%$ & $0.00 \%$ & $18.49 \%$ & $11.20 \%$ & 81.33 & 88.27 & 150.52 \\
\hline & Zero & $10 \%$ & $7.09 \%$ & $36.41 \%$ & $0.00 \%$ & 727.36 & 104.42 & 113.27 \\
\hline & & $20 \%$ & $9.25 \%$ & $30.17 \%$ & $0.00 \%$ & 121.42 & 151.84 & 97.67 \\
\hline & & $25 \%$ & $7.88 \%$ & $27.58 \%$ & $0.00 \%$ & 107.27 & 87.50 & 92.12 \\
\hline
\end{tabular}


Table 5. Average difference and computational time for 7-period cycle instances at 99\% service level.

\begin{tabular}{|c|c|c|c|c|c|c|c|c|}
\hline \multirow[b]{2}{*}{ Service Level } & \multirow[b]{2}{*}{$\begin{array}{l}\text { Ordering } \\
\text { Cost/ } \\
\text { Holding } \\
\text { Cost }\end{array}$} & \multirow[b]{2}{*}{$\begin{array}{l}\mathrm{SD} / \\
\text { Average }\end{array}$} & \multicolumn{3}{|c|}{$\begin{array}{lcc}\begin{array}{l}\text { Average } \\
\text { from Best Solution }\end{array} & \text { Difference } \\
\end{array}$} & \multicolumn{3}{|c|}{$\begin{array}{l}\text { Computational } \\
\text { Time (s) }\end{array}$} \\
\hline & & & Upper & Lower & EOQ & Upper & Lower & EOQ \\
\hline \multirow[t]{9}{*}{0.99} & High & $10 \%$ & $0.00 \%$ & $5.84 \%$ & $5.84 \%$ & 486.16 & 827.66 & 844.09 \\
\hline & & $20 \%$ & $0.00 \%$ & $2.32 \%$ & $2.32 \%$ & 1437.59 & 719.77 & 745.90 \\
\hline & & $25 \%$ & $0.00 \%$ & $3.74 \%$ & $3.74 \%$ & 11458.00 & 1893.64 & 1732.43 \\
\hline & Low & $10 \%$ & $26.65 \%$ & $45.16 \%$ & $0.00 \%$ & 654.94 & 672.63 & 358.24 \\
\hline & & $20 \%$ & $30.52 \%$ & $43.01 \%$ & $0.00 \%$ & 695.42 & 1359.44 & 653.16 \\
\hline & & $25 \%$ & $29.57 \%$ & $43.74 \%$ & $0.00 \%$ & 8220.59 & 1389.48 & 1394.17 \\
\hline & Zero & $10 \%$ & $0.00 \%$ & $70.26 \%$ & $50.34 \%$ & 697.93 & 409.28 & 189.54 \\
\hline & & $20 \%$ & $0.00 \%$ & $45.41 \%$ & $31.98 \%$ & 787.83 & 378.00 & 1491.00 \\
\hline & & $25 \%$ & $0.00 \%$ & $37.80 \%$ & $26.37 \%$ & 617.67 & 469.65 & 668.90 \\
\hline
\end{tabular}

\subsection{Efficiency of Each Alternative on Another Set of Demands}

Initial policies from the first phase and safety stock from the second phase are combined as final ordering policy. These combinations of deterministic policy and safety stock are tested on another scenario with 1,000 periods to compare its robustness with total cost and service level.

Focusing on the robustness of policies, on average for 4-period cycle, average loss is around $0.00 \%$ to $0.19 \%$ for $99 \%$ service level and $0.00 \%$ to $0.22 \%$ for $95 \%$ service level as shown in Fig. 4 and Fig. 5. In a certain period, applying upper and EOQ policies can lead to the maximum loss (not the average loss shown in Figs. 4 and 5) as high as 39.75\% for 99\% service level and $42.58 \%$ for $95 \%$ service level while the maximum loss of lower policies is no higher than $25 \%$ and $30 \%$ respectively. However, the number of periods that loss is higher than the expected service level is smaller than $2 \%$ in a span of 1,000 periods. For 7-period cycle, average loss is around $0.00 \%$ to $0.05 \%$ for $99 \%$ service level as shown in Fig. 6. In a certain period, applying upper and EOQ policies can lead to the maximum loss as high as $23.84 \%$ for $99 \%$ service level while the maximum loss of lower policies is no higher than $18.90 \%$. In a span of 1,000 periods, the number of periods that loss is higher than the expected service level is smaller than $1 \%$. Therefore, the policies obtained from proposed approach are robust for the problem and are practical to use in real life.

When standard deviation increases, the total cost and loss tends to increase. Lower policies give the highest total cost but the lowest loss. Normally, the upper policies tend to give the lowest total cost and highest loss. Lower policies have the highest cost and lowest loss since they have bigger size of orders and hold more inventory than other alternatives. The policies have the bigger size of orders because they have bigger differences between reorder points and order-up-to points. On the contrary, upper and EOQ policies give lower total costs due to their smaller orders leading to lower holding costs. In summary, there is tradeoff between total cost and loss. For cost-concern, upper or EOQ policies are the preferred. For loss-concern, lower policies are the best choices. 


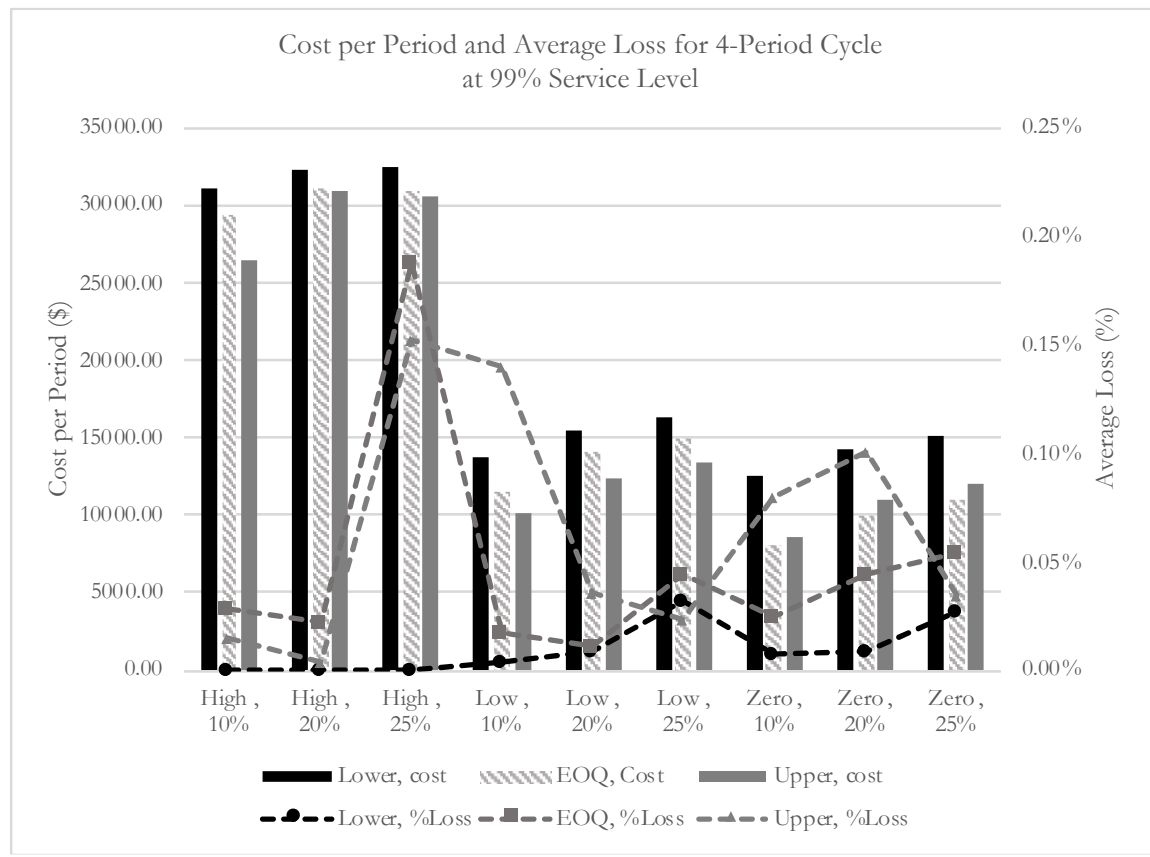

Fig. 4. Total cost and average loss for 4-period cycle instances at 99\% service level on 1,000-period horizon.

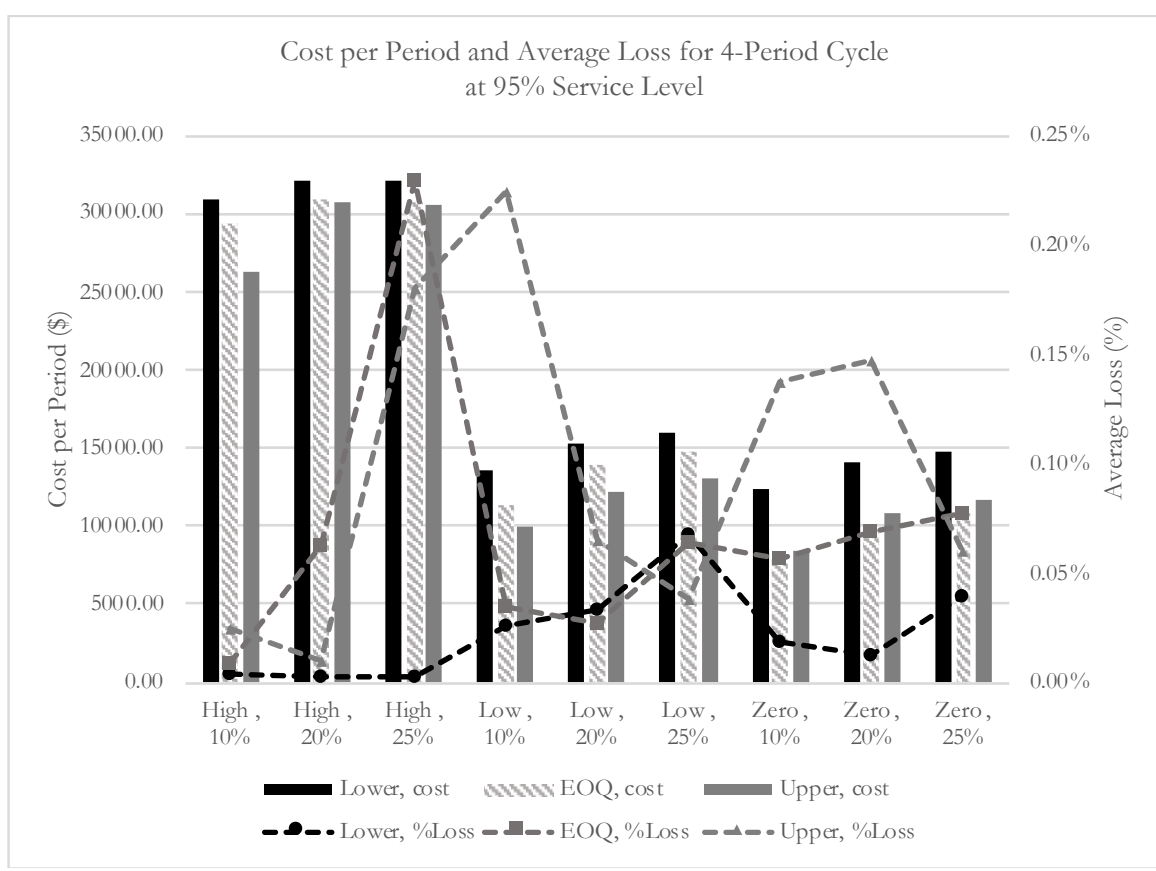

Fig. 5. Total cost and average loss for 4-period cycle instances at 95\% service level on 1,000-period horizon. 


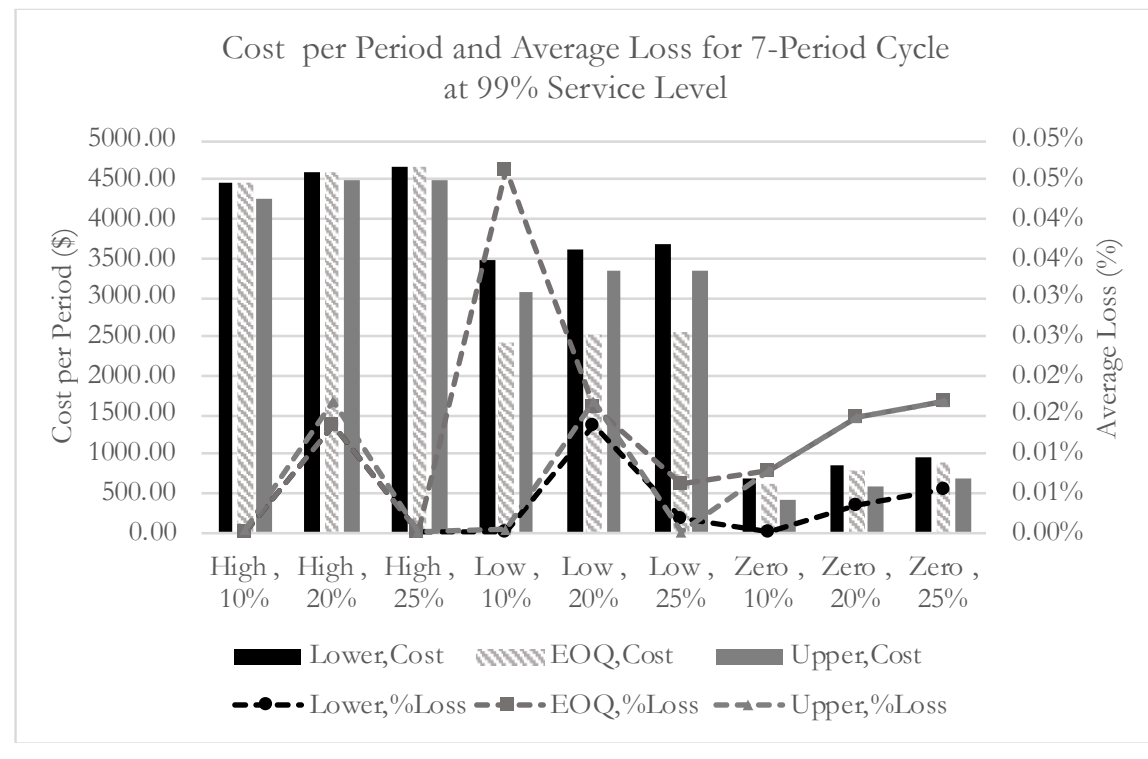

Fig. 6. Total cost and average loss for 7-period cycle instances at 99\% service level on 1,000-period horizon.

\subsection{Effect of On-Hand and On-Order Inventory through Inventory Policy}

Since system operates under periodic review and seasonal demand, some values of initial on-hand inventory may lead to shortage while other values may not, even though they are applied to the same ordering policy. The example in Table 6 illustrates that an ordering policy cannot be applied to every value of initial on-hand inventory. In Table 6, an order is placed at the end of each period. The system has 1-period lead time so an order placed at the end of this period will be ready to use at the end of the next period. The system A with 1,360 initial inventory faces no shortage. On the contrary, the system B with 4,000 initial on-hand inventory faces shortage at period 5. Therefore, under seasonal demand, it is better to find the proper initial on-hand level by letting it be a decision variable than an input parameter. This can help the system avoid shortage.

To implement the $(R, S, S)$ policies with predetermined initial inventory obtained from the algorithm, inventory managers may start using the $(R, S)$ policies first. When the inventory position of any retailer reaches the required level, that retailer can start using $(R, S, S)$ policy. After all retailers use $(R, S, S)$, the warehouse can use its $(R, S, S)$ policy when the echelon inventory position reaches the required level.

Table 6. Example of effect of initial on-hand inventory on shortage.

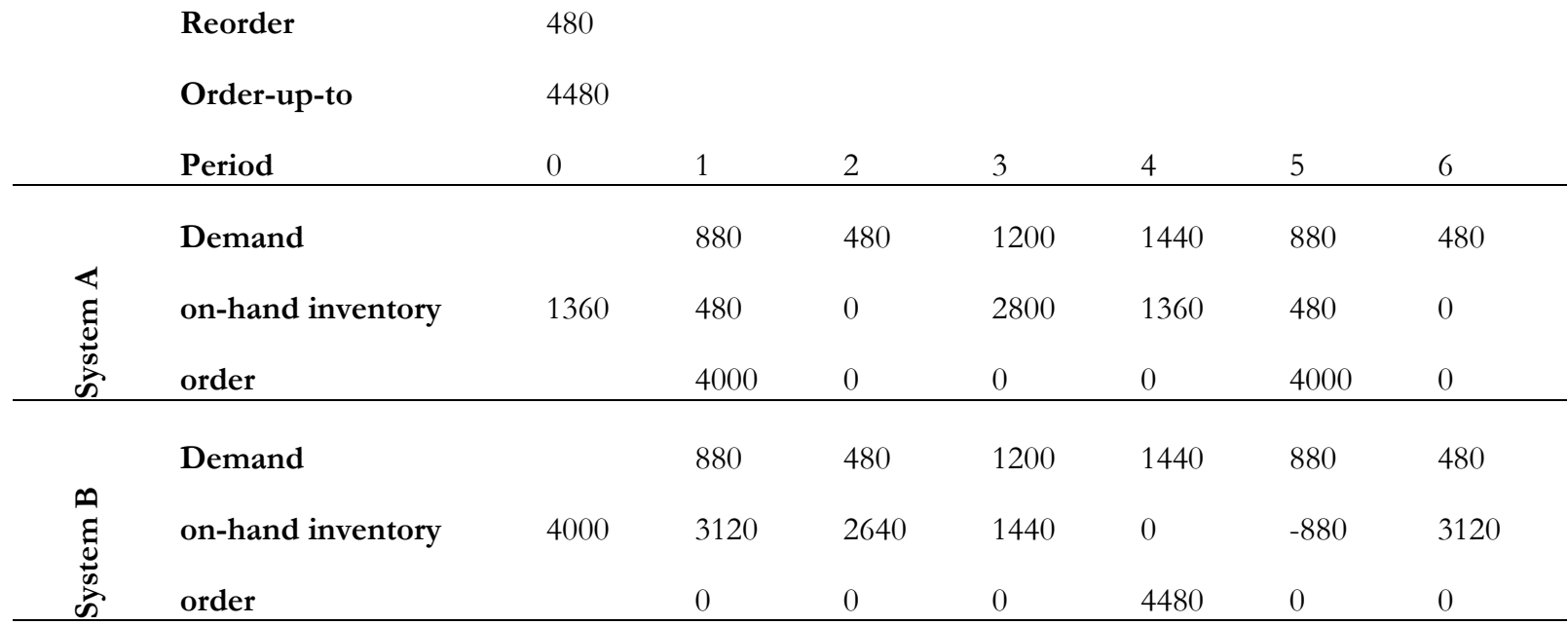




\section{Conclusion}

A methodology to deal with multi-echelon inventory system with seasonal demand is proposed. Since the seasonal stochastic demand cannot be directly solved with a MIP model, the 2-phase methodology is proposed. The first phase determines deterministic policy by solving a deterministic problem based on average demand and the second phase calculates safety stock by solving multiple scenarios of the problem generated from demand distribution. The MIP model for the first phase is used to find reorder and orderup-to points. We found that there are alternative optimal solutions where multiple reorder points provide the same total cost. However, these alternatives may lead to different cost in the second phase. Therefore, we explore 3 different alternatives from the first phase including lower, upper and EOQ. In the second phase, another MIP model is developed. It uses reorder and order-up-to points from phase 1 as inputs and solves multiple randomly-generated scenarios simultaneously for safety stock that leads to the minimum total cost respected to required service level.

The proposed methodology can find solutions within a reasonable amount of time (generally within 15 minutes). The policy with the highest reorder point tends to get the lowest cost in most scenarios but they face more demand loss comparing to other policies. On average, when the upper-alternative policies is the best policy, it gives the total cost that is around $17 \%$ better than other policies. On the other hand, the policy with the lowest reorder point tends to get the highest cost but the lowest demand loss. The highest average loss from the lower-alternative policies is only $0.07 \%$ while the highest average loss from other policies is $0.22 \%$.

As the problem that we considered in this paper assumed that unsatisfied demand was lost and the problem with lost-sales assumption received more attention recently [27], to make the problem be more interesting, it can be extended in various aspects such as considering shortage cost, considering ordering batch sizes, exploring other replenishment policies or exploring other replenishment modes. The methodology can be improved as well. The proposed methodology based upon MIP models can solve only limited problem size. While the problem sizes increase such as increasing in demand volume or increasing in the number of periods per cycle, the optimal solution may not be able to obtain using the MIP models. Heuristic approach should be developed to solve the problem.

\section{Acknowledgement}

The Scholarship from the Graduate School, Chulalongkorn University to commemorate the $72^{\text {nd }}$ anniversary of his Majesty King Bhumibala Aduladeja is gratefully acknowledged.

\section{References}

[1] E. A. Silver, D. Pyke, and R. F. Peterson, "Forecasting," in Inventory Management and Production Planning and Scheduling, 3rd ed. New York: John Wiley and Sons, 1998, ch. 4, pp. 75-148.

[2] J. E. Hanke and D. W. Wichern, "Exploring data patterns and choosing a forecasting technique," in Business forecasting, 8th ed. New Jersey: Prentice Hall, 2005, ch. 3, pp. 57-100.

[3] A. J. Clark and H. Scarf, "Optimal policies for a multi-echelon inventory problem," Management Science, vol. 2, pp. 475-490, 1960.

[4] A. Federgruen and P. Zipkin, "Computational issues in an infinite-horizon, multiechelon inventory model," Operations Research, vol. 32, no. 4, pp. 818-836, 1984.

[5] M. A. De Bodt and S. C. Graves, "Continuous-review for a multi-echelon inventory problem with stochastic demand," Management Science, vol. 31, no. 10, pp. 1286-1299, 1985.

[6] S. Mitra and A. K. Chatterjee, "Echelon stock based continuous review (R,Q) policy for fast moving items," Omega, vol. 32, pp. 161-166, 2004.

[7] S. A. Bessler and A. F. Veinott, "Optimal policy for a dynamic multi-echelon inventory model," Naval Research Logistics Quarterly, vol. 13, no. 4, pp. 355-389, 1965.

[8] G. Eppen and L. Scharage "Centralized ordering policies in a multi-warehouse system with lead times and random demand," TIMS Studies in the Management Sciences, vol. 16, pp. 51-67, 1981.

[9] S. Bollapragada, R. Akella, and R. Srinivasan, "Centralized ordering and allocation policies in a twoechelon system with non-identical warehouses," European Journal of Operational Research, vol. 106, pp. 7481, 1998. 
[10] A. Federgruen and P. Zipkin, "Approximations of dynamic multilocation production and inventory problems," Management Science, vol. 30, pp. 69-84, 1984.

[11] N. Erkip, W. H. Hausman, and S. Nahmias, "Optimal centralized ordering policies in multi-echelon inventory systems with correlated demands," Management Science, vol. 36, no. 3, pp. 381-392, 1990.

[12] W. Zangwill, "A backlogging model and a multi-echelon model of a dynamic economic lot size production system - A network approach," Management Science, vol. 15, pp. 506-527, 1969.

[13] M. Diaby, and A. Martel, "Dynamic lot sizing for multi-echelon distribution systems with purchasing and transportation price discounts," Operations Research, vol. 41, no. 1, pp. 48-59, 1993.

[14] W. Jaruphongsa, S. Cetinkaya, and C-.Y. Lee, "A two-echelon inventory optimization model with demand time window considerations," Journal of Global Optimization, vol. 30, pp. 347-366, 2004.

[15] M. Afzalabadi, A. Haji, and R. Haji, "Vendor's optimal inventory policy with dynamic and discrete demands in an infinite time horizon," Computers and Industrial Engineering, vol. 102, pp. 368-373, 2016.

[16] A. Kovalev and C. T. Ng, "A discrete EOQ problem is solvable in $\mathrm{O}(\log \mathrm{n})$ time," European Journal of Operational Research, vol. 189, pp. 914-919, 2008.

[17] S. A. Tarim and B. G. Kingsman, "The stochastic dynamic production/inventory lot-sizing problem with service-level constraints," International Journal of Production Economics, vol. 88, pp. 105-119, 2004.

[18] J. H. Bookbinder and J.-Y. Tan, "Strategies for the probabilistic lot-sizing problem with service-level constraints," Management Science, vol. 34, no. 9, pp. 1096-1008, 1988.

[19] S. A. Tarim and B. G. Kingsman, "Modelling and Computing $\left(\mathrm{R}^{\mathrm{n}}, \mathrm{S}^{\mathrm{n}}\right)$ policies for inventory systems with non-stationary stochastic demand," European Journal of Operational Research, vol. 174, pp. 581-599, 2006.

[20] S. A. Tarim and B. M. Smith, "Constraint programming for computing non-stationary (R, S) inventory policies," European Journal of Operational Research, vol. 189, pp. 1004-1021, 2008.

[21] S. C. Graves and S. P. Willems, "Strategic inventory placement in supply chain: Nonstationary demand," Manufacturing and Service Operation Management, vol. 10, no. 2, pp. 278-287, 2008.

[22] S. C. Graves and S. P. Willems, "Optimizing strategic safety stock placement in supply chains," Manufacturing and Service Operation Management, vol. 2, pp. 68-83, 2000.

[23] A. M. Reddy and C. Rajendran, "A simulation study of dynamic order-up-to policies in a supply chain with non-stationary customer demand and information sharing," International Journal of Advance Manufacturing Technology, vol. 25, pp. 1029-1045, 2005.

[24] G. Kim, K. Wu, and E. Huang, "Optimal inventory control in a multi-period newsvendor problem with non-stationary demand," Advanced Engineering Informatics, vol. 29, pp. 139-145, 2015.

[25] C. S. Grewal, S. T. Enns, and P. Rogers, "Dynamic reorder point replenishment strategies for a capacitated supply chain with seasonal demand," Computers and Industrial Engineering, vol. 80, pp. 97-110, 2015.

[26] H. Tunc, O. A. Kilic, S. A. Tarim, and B. Eksioglu, "The cost of using stationary inventory policies when demand is non-stationary," Omega, vol. 39, pp. 410-415, 2011.

[27] T. de Kok, C. Grob, M. Laumanns, S. Minner, and J. Rambau, "A typology and literature review on stochastic multi-echelon inventory models," European Journal of Operational Research, vol. 269, pp. 955983, 2018.

[28] S. Nahmias, "Inventory control subject to uncertain demand," in Production and Operations Analysis, 6th ed. New York: McGraw-Hill, 2009, ch. 5, pp. 248-310. 